\title{
Высокоэффективные квазиоптические частотные фильтры ТГц диапазона на основе частотно-избирательных поверхностей
}

\author{
С.А. Кузнецов ${ }^{1,2}$, А.В. Гельфанд ${ }^{1}$, П.А. Лазорский ${ }^{1}$, В.Н. Федоринин ${ }^{1}$, А.В. Аржанников ${ }^{2,3}$, \\ Н.А. Николаев ${ }^{2,4}$, А. А. Мамрашев ${ }^{4}$, А.А. Рыбак ${ }^{2,4}$, А.Н. Генцелев ${ }^{3}$, В.П. Бессмельцев ${ }^{4}$ \\ ${ }^{1}$ Новосибирский филиал Института физики полупроводников им. А.В. Ржанова СО РАН "КТИПМ", \\ Новосибирск, 630090, пр. Академика Лаврентьева, 2/1 \\ ${ }^{2}$ Новосибирский государственный университет, Новосибирск, 630090, Пирогова, 2 \\ ${ }^{3}$ Институт ядерной физики им. Г.И.Будкера СО РАН, Новосибирск, \\ 630090, пр. Академика Лаврентьева, 11 \\ ${ }^{4}$ Институт автоматики и электрометрии СО РАН, Новосибирск, \\ 630090, пр. Академика Коптюга, 1 \\ тел:+7 (383)363-42-95, эл. почта: sakuznetsov@nsu.ru
}

DOI 10.34077/RCSP2021-48

В последнее десятилетие происходит активное освоение терагерцового диапазона частот электромагнитного спектра $(0,1-10$ ТГц), стимулированное развитием эффективных методов генерации и детектирования ТГц излучения. Данная спектральная область, простирающаяся от коротковолновой части миллиметрового диапазона до дальнего ИК ( $\lambda=0,03-3$ мм), представляет большой практический интерес ввиду ряда уникальных свойств. К ним относятся отсутствие ионизирующего эффекта, сравнительно высокая проникающая способность во многие оптически непрозрачные материалы, высокая чувствительность к металлическим и водным средам, возможность достижения мм/субмм пространственного разрешения при визуализации скрытых объектов, наличие вращательных переходов в молекулах ряда важных органических веществ, высокая информационная ёмкость при передаче данных. Указанные свойства делают ТГц волны перспективными для систем безопасности, неразрушающего контроля и диагностики материалов, биомедицинских технологий, новых поколений систем связи $(6 \mathrm{G}, 7 \mathrm{G})$, и др.

Успешное решение задач ТГц фотоники предполагает необходимость частотной фильтрации квазиоптических пучков ТГц излучения для выделения нужного спектрального интервала. С инструментальной точки зрения ТГц диапазон удобно позиционирован между примыкающими к нему СВЧ и ИК областями, поскольку позволяет сочетать в ТГц аппаратуре инструментальные решения как оптической, так и микроволновой техники. Примером таких решений служат тонкие планарные метало-диэлектрические структуры субволновой топологии, известные в микроволновой литературе как «частотно-избирательные поверхности» (ЧИП), а в физике метаматериалов - как «метаповерхности». ЧИП являются, как правило, резонансными электродинамическими структурами, работающими на локализованном плазмонном резонансе, и эксплуатируются в режиме, когда их характерные резонансные частоты лежат ниже точки возбуждения высших дифракционных гармоник, что отличает такие структуры от дифракционных решеток. Последнее достигается малостью периода расположения элементарных ячеек ЧИП в ее латеральной плоскости в сравнении с рабочей длиной волны. При этом характерные топологические размеры микрорисунка ЧИП имеют масштаб от единиц до сотен микрометров, что позволяет использовать для качественного производства ЧИП хорошо отработанные технологии микроструктурирования.

В настоящей работе освещаются теоретические, технологические и прикладные аспекты выполненных в Новосибирском научном центре разработок высокоэффективных ЧИП структур для фильтрации излучения в области частот 0.07-3 ТГц. Рассмотрены фильтры различных типов: полосовые пропускающие (band-pass), полосовые режекторные (band-stop), фильтры высоких частот (high-pass), фильтры низких частот (low-pass), фильтры Фабри-Перо. Для указанных фильтров: a) представлены результаты анализа электродинамических особенностей ЧИП, которые следует учитывать для получения структур с наиболее эффективными фильтрующими свойствами; б) рассмотрены особенности производства с применением технологий фотолитографии, гальванопластики, глубокой рентгеновской литографии, микроструктурирования посредством фемтосекундных лазерных импульсов; в) рассмотрены особенности спектрального тестирования техникой ЛОВ-, Time-Domain и Фурье-спектроскопии; г) приведены примеры использования в ТГц метрологических системах. Показано, что разработанные устройства являются лучшими на рынке российских ТГц технологий. 